IBT Journal of Business Studies

Volume 14(2), 77-89, 2018

\title{
A Qualitative Research On Individual Barriers to Knowledge Sharing: Causes and Remedies A Health-Care Sector Based Study
}

\author{
Muhammad Abdul Basit-Memon ${ }^{1}$ \\ Manzoor Ali Mirani ${ }^{2}$ \\ Shahid Bashir ${ }^{3}$
}

\begin{abstract}
Management and sharing of knowledge has been among the top most strategic priorities of the organizations, due to its generally acknowledged role toward the improvement of organizational performance, accomplishment of organizational goals and achievement of competitive advantage. However, most of the organizations, despite spending huge budgets on the implementation of quality knowledge management systems, fail to enjoy the benefits of knowledge sharing due a number of individual organizational and technological barriers that impede the successful sharing of knowledge. Hence, it seems extremely important to understand the factors that impede the knowledge sharing and foil the successful implementation of knowledge management systems. This study has been conducted to empirically investigate the individual barriers to knowledge sharing. Based on 75 qualitative interviews within three health-care organizations of the capital of Pakistan, this research has identified unwillingness to share, lack of motivation, time deficiency, absence of trust, cultural dissimilarity and lack of a common language as some of the most significant individual barriers to knowledge sharing. This study has not only identified the barriers, but, also the remedies to knowledge sharing in the light of the recommendations from the interviewees.
\end{abstract}

KEYWORDS: Knowledge Sharing, Individual Knowledge Sharing Barriers, Remedies to knowledge Sharing Barriers, Unwillingness to Share, Trust, Motivation, Cultural and Language Differences.

1- Lecturer Sukkur IBA University, m.memon@mdx.ac.uk

2- Professor Sukkur IBA University, manzoor@iba-suk.edu.pk

3- Assistant Professor, SZABIST Islamabad, Sahidbashir_uk@yahoo.com 


\section{INTRODUCTION}

Knowledge has been increasingly perceived as the most crucial strategic resource for organisations and a significant base for attaining competitive edge (Siakas, Georgiadou, \& Balstrup, 2010). Knowledge management is a methodical and organized process of locating, collecting, storing, creating and disseminating organizational knowledge to individuals and units in order to achieve organizational goals of efficiency, effectiveness in all organizational functions and performance related aspects (Alavi \& Leidner, 2001). Creation, acquisition and dissemination of knowledge is a decisive prerequisite for the success of projects of different types in today's dynamic and volatile business environment. Knowledge according to Davenport and Prusak (1998) 'is a combination of knowhow, insights, experience values and circumstantial information that offers a structure for assessing and integrating fresh information and experience' (p.4). Knowledge can be in written, processed or codified form (explicit knowledge) or an intangible form including, know how, experience and insights remaining in the minds of individuals (tacit knowledge).

On the other hand, this is notable that despite growing emphasis on knowledge management and knowledge sharing, most of the companies fail to properly leverage the benefits of the same (Kukko, 2013). This is because of the fact that the management of knowledge is not that simple; rather it involves a number of individual and organizational barriers that defeat the successful implementation of knowledge management programs and endeavours of the organizations (Yesil et al., 2013; Vajjhala, 2013; Riege, 2005; Lindsey, 2003). This means that the ignorance regarding these barriers to knowledge sharing results into a number of potential problems and losses of resources and energies. It also seems strange that despite globally recognized status of knowledge management and roaring of impressive slogans in the favour of knowledge sharing, like icon of the 21 st century, very little focus has been given toward understanding the factors that thwart the effective sharing of knowledge within organizations. Hence, for organizations to truly enjoy the associated benefits of knowledge sharing, it looks imperative to understand these barriers to knowledge sharing. The ability of the firms to recognize and understand these barriers could enable them to efficiently direct their actions and resources towards foiling such hurdles from arising and eradicating the already existing barriers in the workplace (Kukko, 2013).

A critical review of the recent studies on barriers to knowledge sharing reveals the fact that most of the studies revolve around corporate culture (e.g. McDermott and O'Dell, 2001; De Long and Fahey, 2000) or national culture (e.g. Dulaimi, 2007; Moeller \& Svahn, 2004; Michailova \& Husted, 2003; Husted \& Michailova, 2002) leaving the comprehension of individual barriers to knowledge sharing being almost unexplored. Moreover, a thorough analysis of the available literature presents some research papers on this topic, but there are a number of limitations. First, most of the research papers are review or conceptual papers and secondly most of the research studies on barriers to knowledge sharing have been conducted in Western context with very few studies being conducted in Asian and especially in South Asian context. Thirdly, existing studies discuss barriers to knowledge sharing in a mixed form, merging organizational, individual and technological factors together and because of that, it creates an element of confusion for the readers to discern individual and organizational barriers to knowledge sharing. Based on the above explanation, it looks extremely important to make some empirical contributions to help the managers and practitioners to understand the individual barriers to knowledge sharing and this research is conducted with the same spirit. Hence, this study has been conducted to separately understand and analyse individual barriers to knowledge sharing in a professionalized context i.e. health care sector and contributes toward the existing body of literature on knowledge management. An idiosyncratic feature of this research is that unlike most of the existing studies on barriers to knowledge sharing, this is conducted in South Asian context. Another distinctive feature of this paper is that it is not limited to the identification of barriers to knowledge sharing, but, it also discusses remedies towards the barriers in the light of the recommendations of the respondents and hence provides some insightful implications for managers and practitioners especially in the field 
of health care. The remaining of the paper is as follows: next section presents a brief account of the existing literature and empirical analysis of the research studies on individual barriers to knowledge sharing. After the next section, research methodology is discussed, followed by research findings on individual barriers to knowledge sharing and their remedies as suggested by the respondents. The last section provides a very fruitful discussion and implications for managers and practitioners.

\section{THEORETICALBACKGROUND}

Barriers to knowledge sharing endanger the individuals' and organizations' efforts and initiatives of promoting knowledge management and deprive them from the positive fruits of knowledge transfer (Lindsey, 2006). Many companies have found the process of knowledge management chaotic and complicated, due to a number of problems and barriers that impinge the smooth the process of knowledge management (e.g., Zawawi, et al., 2011; Kimble, et al., 2010; Bradfield \& Gao, 2007; Lindsey, 2006; Christensen, 2007; Riege, 2005). Obstacles in knowledge transfer can adversely affect competitiveness and creativity in firms (Vajjhala, 2013). That is why, Riege (2005) has urged the organizations to pay a serious attention towards knowledge sharing barriers if they are sincere in making knowledge sharing a success within their firms. Since this paper is aimed at investigating the individual barriers, therefore, the discussion will revolve around individual barricades to knowledge sharing. In the process of knowledge sharing, the role of individuals is the most critical; particularly with respect to sharing of tacit knowledge which tends to be free from the boundaries of explicit or codified knowledge and resides in the brains of the individuals. Collaborative ties within organizations develop due to interactions, decisions and interpersonal relationships among individuals working within organizations rather than organizational initiatives only (Zhang \& Daves, 2006; Ring \& Van de Ven, 1994). This is why, KPMG, a world renowned consulting firm suggested that blocked channels between knowledge holders and knowledge seekers is the most critical barrier to knowledge sharing within organizations. Findings of Lin et al (2008) also endorse the findings of KPMG. Hence, individual factors are very important in the discussion of barriers to knowledge sharing.

The available literature enlists a number of individual barriers to knowledge, such as lack of trust (Renzel 2008; Mooradian et al., 2006; De Long and Fahey, 2000); one's over emphasis on his or her power or position in organization (Santos et al., 2012; Rowley, 2002; Murray, 2002); lack of communication skills (e.g. Lindsey 2003; Meyer, 2002; Hendriks, 1999); lack or weak social networks (e.g. Nahapiet and Ghoshal, 1998; Ingram and Baum, 1997; Argote et al., 1990); variances of national culture (Finestone \& Snyman, 2005; Michailova and Husted, 2003; Ford \& Chan, 2002) and lack of time (O'Dell \& Grayson, 1998; Gold et al., 2001). In the study of Santos et al (2012) conducted in Portugal, found the problem of codification of knowledge, lack of time and lack of initiative and strategy by the co-workers as the most important individual barriers to knowledge sharing. According to their findings, many participants reported lack of spirit and lack of enthusiasm and initiative for sharing knowledge. Codification of knowledge in the view of the participants was also a big barrier to sharing of knowledge. Zhang \& Daves (2006) identified lack of clearance of organizational goals, lack of time and lack of confidentiality as individual barriers to KS. From the context of medical profession, Detmer and Shortliffe (1997) believed that ignorance regarding available knowledge, lack of access to that knowledge, lack of time and poor organization of the available knowledge are barriers to exchange of medical knowledge. In another study conducted by Lin et al (2008) in health care organizations, lack of willingness to share the knowledge due to maintenance of prestige and competitive position in the organization were identified as barriers to knowledge sharing from sharers perspective. And from the receivers perspective, lack of belief in the authenticity of the shared knowledge, lack of positive attitude towards sharing knowledge, lack of absorptive capacity were the key barriers and from combined point of view, poor relationship between sharer and receiver of knowledge were identified as individual barriers to knowledge sharing (Lin et al., 2008). In another study Lilleoere \& Hansen (2011) in pharma industry, found lack of appreciation, 
lack of wakefulness regarding the availability of knowledge, fear of being perceived as foolish due to sharing the knowledge and considering knowledge as a source of power as the main hurdles in knowledge sharing.

\section{RESEARCH METHODOLOGY}

When the research aims at learning a phenomenon and understanding its characteristics, instead of verifying predetermined hypothesis, it is more suitable to adopt qualitative approach to research project (Levy et al., 2010). Keeping in view the nature of the study, purposive selective sampling technique (Wilmot, 2005) was chosen and a sample of 75 interviewees was selected from three healthcare organizations of Islamabad, the capital of Pakistan. Semi-structured interviews were conducted for collection of data due to their suitability appropriateness for data collection ((Blaxter et al., 1996; Patton, 1990).Case study research strategy was adopted. Case study method is applied for generating rich data and detailed analysis of a particular phenomenon of interest, based on the empirical investigation of a small number of cases/organizations/entities (Eisenhardt 1989). In order to ensure rigor and quality of research, instead of single, multiple case study method was applied (Stake, 2006). The interviewees included doctors, nurses and other senior administrative staff. The interviews were recorded and then transcribed. A pilot study was conducted and some doctors and nurses were interviewed to understand the suitability of the questions to be asked in the interviews. The interviews included the questions on the status of knowledge sharing, knowledge sharing processes within the case organizations; the antecedents to knowledge sharing and the barriers to knowledge sharing. Interviews averagely lasted for 45 minutes. All interviews were recorded and transcribed later on for data analysis. The data was analysed through thematic analysis (Christensen et al., 2008; Kvale, 1996). While analysing the data the Braun \& Clarke's (2006) suggested guideline was adopted. In the first step of data analysis, the important codes were identified, in the second stage, themes were generated in the light of the codes and in the third stage categories were identified and in the fourth stage, all the interviews were analysed and similar codes and themes were merged in the identified categories in order to understand the whole data and then in the final stage a complete data analysis report was generated in the light of the research questions and research objectives. Before reaching the final data analysis report the whole process of data analysis was cross-checked by two senior researchers.

\section{FINDINGS}

\section{Unwillingness to Share}

The most critical barrier towards knowledge sharing tends to be the factor of unwillingness of the organizational members to share their knowledge and it can be due to a number of reasons/factors. An important and one of the most commonly observed reasons of avoidance to share the knowledge relates to the factor of perceiving knowledge as a source of power and organizational power-position or impression building (Lilleoere \& Hansen, 2011; Zhang \& Daves, 2006; Bartol and Srivastava, 2002; O'Dell \& Grayson, 1998). Retention of knowledge is perceived to be a source of competitive advantage over other colleagues or as cited in the words of Francis Bacon that 'knowledge is power' so, nobody wants to lose his or her power.

The factor of unwillingness includes the element of certain potential risks involved with regard to the sharing of knowledge especially the sharing of some very specialized or specified nature (Rosen, Frust \& Blackburn, 2007). For example, there is possibility of lack of reciprocity in the process of knowledge sharing. It also involves sharing of incorrect knowledge by the receiver, putting the repute of the sharer at stake. There is a quite visible issue of the misuse or unauthorized use of shared knowledge by the recipients. This has been witnessed in a number of cases that the receivers try to capitalize on the shared knowledge of some of their colleagues by promoting their knowledge to 
others and giving the impression as if they were the originators or the prime sharers of that knowledge. They may try to impress their management or other colleagues through giving impressive power point based presentations and pretend to have explored those wonderful ideas, which actually were shared by some of their colleagues. Some others may even use that knowledge against the sharer if that knowledge tend to have some sensitive contents in it. When teammates smell the unfair and unauthorized scrutiny and use of their contributions towards their colleagues, then they might uphold the sharing of specialized knowledge, concentrating only on sharing of commonly available knowledge (Rosen, Frust \& Blackburn, 2007). The participants shared such concerns, risks and fears regarding sharing of knowledge. 'I don't believe in knowledge sharing. I thought to write a research article on a particular topic and I discussed the whole research idea with one of my colleagues and before I get the time to write the paper, my colleague wrote the research paper on the same topic and got published, leaving me disappointed'(R 23). Another male nurse reported, I shared some knowledge with one of my colleagues and they used the same against me later on and hence I decided not to share knowledge with my colleagues ( $\mathrm{R}$ 58).In the views of another respondent knowledge sharing is always risky because you never know the intentions of the individual with whom you are going to share your knowledge' (R 28).

\section{Lack of Trust}

A number of respondents reported lack of trust as a very critical reason of not sharing the knowledge. According to them, trust is very important factor for any fruitful communication and meaningful exchange of thoughts or ideas. Hence, they told that they do not share the knowledge with their colleagues whom they do not trust. Since Pakistani society is a multi-cultural society, therefore, the importance of trust further increases; because many individuals don't easily trust their colleagues and hence they restrict sharing of knowledge only with the people whom they trust. The participants gave similar kinds of responses. For example, a young doctor said 'I don't share the knowledge with the one whom I don't trust. Knowledge is your asset and you will share the same only with one whom you trust'(R 8). Another senior female nurse said 'Although in our profession, we are bound to share the knowledge for the safety and recovery of patient and hence we have to share in any case. However, when I am free to share or not, I mean when I have to share the knowledge voluntarily, then I don't share my knowledge with the ones whom I don't trust' (R 63).

\section{Lack of Motivation}

Sharing of knowledge is a kind of voluntary activity. It involves a lot patience and sacrifice. It involves sacrifice of time, sacrifice of energy and sacrifice of temperament (if the receiver is non-serious or indecent person) and it involves a number of risks also. Hence, after accepting so many risks and sacrifices, an individual will only be willing to share the knowledge if he or she gets proper reward or motivation from the colleagues or the organization. According to the viewpoint of the majority of respondents in the current study, the management especially with respect to knowledge sharing does not motivate them. Neither, they are facilitated with proper logistic support of required tools and resources including seminar rooms, free time slots and audio-visual aids and free rooms and places for knowledge sharing; nor they are motivated and encouraged through financial or nonfinancial incentives to gain new knowledge or higher degree to be able to share their knowledge with others. These responses highlight the concerns of respondents regarding their feelings of lack of motivation: There is no motivation or inducement for knowledge sharing here at our hospital. Management has no interest. They never organize seminars or knowledge sharing sessions nor do they motivate us for the same' (R 37). Another female nurse said: 'They do not motivate or facilitate us for gaining higher education. I applied for leave to pursue my higher education, but they rejected my application twice. It resulted in a sense of deprivation and disappointment' ${ }^{\circledR} 72$ ). 


\section{Time Constraint}

Lack of time is one of the biggest impediments to knowledge sharing which translates into unwillingness to share. At most of the organizations, staff members have a general complaint regarding lack of time for knowledge sharing (Lugger \& Kraus, 2001) and same are the findings of this research. This is also due to a perception that knowledge sharing is an extra activity and it is not tied to their routine work (du Plessis, 2005). These days everyone seems busy. The challenges of modern life, stress of increasing needs and limited resources have made almost everyone to become like a machine and the same reflects in the answers of the respondents. 'We get very meagre salaries and due to that we always remain in pursuit of part-time jobs and as a result of that we don't get the time to read latest knowledge in our field and due to not being updated we don't feel confident to share our knowledge with our colleagues' ( $\mathrm{R} 45)$. A number of respondents reported that they are overburdened with work and due to that they don't get the time to share the knowledge. 'I am a doctor and registrar also. I see the patients and look after a number of administrative tasks. How can I get time to share the knowledge? We are generally overburdened with organizational duties, to the extent that we don't get the time to relax, sit and share the knowledge with our colleagues' (R 66). Junior doctors also complained that their seniors don't spare time to properly train and guide them 'Everyone is running behind money and people have no time to share the professional knowledge except the mandatory type of knowledge' ( $R$ $30)$.

\section{Cultural Differences}

Pakistan is a multicultural society comprising five ethnically based states and containing additional ethnic groups within each state. The major five ethnic groups are Punjabi, Pushtoons, Sindhies, Balochi and Gilgiti settled in the respective provinces of Punjab, Khyber Pakhtoonkhaw, Sind, Balochistan and Gilgit Biltistan. All these ethnic groups and other within-states ethnic groups like Urdu Speaking (within Sind) Siraekies (within Punjab), Hindko and Chitrali (within Khyber Pakhtoonkhaw) Makrani and Brohi (within Balochistan) possess their distinctive cultural traditions, values, dresses and speak different languages. Sometimes these cultural differences result into ethnic polarization and conflicts. These cultural differences can result into a barrier towards knowledge sharing. Since this study was conducted in the hospitals of the capital of Pakistan, which employ the individuals belonging to various states and ethnic origins, therefore, a number of participants of the study have mentioned culturally based differences as a big barrier towards knowledge sharing. For example, a senior lady doctor said 'If you ask me, I would like to say that cultural differences are a big barrier towards knowledge sharing. People are seen to be culturally biased towards others regarding knowledge sharing' (R 48). According to the participants, most of the people live and move within the circle of their own community, it hampers the interaction within the colleagues, and it impedes the sharing of knowledge sharing. 'Most people remain within their community groups. I have seen my colleagues to be very much biased and discriminatory regarding sharing of knowledge based on ethnic basis' (R 50). The respondents also reported that people look indifferent while sharing of common knowledge, but, when they have to share some valuable knowledge, then they become biased and share with their own community members only. 'I have seen my colleagues preferring their own ethnically close colleagues for knowledge sharing. For sharing common knowledge, they pretend to be indifferent, but when it comes to specified kind of knowledge, they prefer to share with the people who speak their own language and belong to their ethnic origin' (R 68).

\section{Language Barriers}

Like cultural barriers, the participants in the current study have frequently reported language barriers. Being a multi-cultural country, a number of different languages are spoken in Pakistan, including: Punjabi, Sindhi, Pushto, Balochi, Siraeki, Bilti, Hindko etc. Although the national language of Pakistan is Urdu and the official language of the country is English, but, the people of many areas of 
the country especially those belonging to rural and remote areas tend to be weak both at Urdu and English and feel difficulty in communicating with their country-fellows. Hence, a number of participants of the study have mentioned language differences as a big barrier towards knowledge sharing. 'I am from Chitral, I am weak both at Urdu and English, because of that I face a number of communication problems, and that causes a serious hurdle in knowledge sharing and reduces my confidence' (61). They reported that when the sharing of some specified knowledge comes into play, the racial and ethnic biases come to play their role. 'We are rural people and we are naïve and simple people. However, the people of Islamabad are very shrewd. They speak with us in Urdu while sharing common knowledge with us and when they have to speak about some specific knowledge, they start speaking in their native languages' (R 74). The participants reported that some of their colleagues use hidden codes while talking to others. Only the people who speak their language can understand those codes. 'Some people use hidden codes while talking within a multi-ethnic group of colleagues. The members belonging to their ethnic community might decode those hidden codes. This leads towards big frustration' (R 57). Moreover, some people tend to have the tendency of speaking in their native languages while talking to others in an open forum and that results into big frustration and embarrassment for others. 'Some of our Pushtoon colleagues have a by-birth tendency that while talking to non-Pushtoons, suddenly start talking in their native language Pushto and hence cause a serious problem among their non-Pushtoon colleagues' (R 46). A doctor told that 'One of our senior consultant Pushtoon doctor even used to communicate in Pushto language in the presence of nonPushtoon doctors while going on the patient wards visits and it discouraged many non-Pushtoon doctors and they decided not to go into the visits with that doctor' (R 52).

\section{Suggestions and Recommendations for Remedies}

The researchers discussed about the possible remedies of the barriers to knowledge sharing with the respondents and they suggested a number of valuable suggestions. Firstly, with respect to unwillingness for sharing of knowledge, the participants suggested to create a culture of trust, sense of belongingness and cooperation among organizational members. The participants highlighted the factor of trust more than anything else. This is because of the fact that trust reduces the fear of the various types of risks generally considered by the sharers of knowledge in most of the cases while sharing the knowledge, as discussed above. As a senior male nurse mentioned, 'Knowledge sharing can be possible only in a trusting environment. If you trust management and management trusts you then you start trusting your colleagues also and vice versa' (R 38). The respondents while discussing about the individual factors that reduce the trends of hoarding and non-sharing, recommended modifying the attitude of organizational members towards knowledge sharing. They also emphasized to infuse a sense of professionalism, organizational commitment and a sense of achievement through coaching, careful supervision and mentorship. According to a senior consultant, The management needs to change the mindset of the employees. They need to tell them that it is better for them to share the knowledge, since only through sharing the knowledge, they will be able to understand the accuracy and authenticity of their knowledge' (R 53). Another HR manager suggested, 'we need to cultivate a sense of organizational commitment and professional attitude if we want to encourage them to share the knowledge' (R 26). For the problem of time, participants recommended free time slots and certain number of working hours from every day working exclusively dedicated for knowledge sharing. While showing their concern regarding stressful working environment, they recommended lessening of working hours and implementation of organizational rules and regulations and the principles of justice and fairness with regard to hiring, firing, promotions and assigning of duties.

While commenting on the ethnic and language based issues and problems, participants suggested to eliminate and minimize ethnic differences through promoting national thinking, encouraging collective way of thinking and supporting national language i.e. Urdu. They once again emphasized on creating an organizational culture of interpersonal trust and confidence. They highlighted that trust 
reduces the feelings of strangeness from among the organizational members and cultivates a feeling of respect, likeness and collaboration among culturally diversified employees. Another suggestion with respect to mitigating the trends of hoarding and unwillingness was that of motivation and incentives. The participants frequently pointed out financial and nonfinancial incentives as well as coercive measures for overcoming the trends of knowledge hoarding and not sharing. Incentives included with and without pay study leaves and scholarships for higher education, and other organizational rewards or impressive titles like employee of the month and "most knowledgeable person of the month" or the year; based on individuals' contributions and services for promoting knowledge sharing and facilitating and guiding their colleagues in the connection of their knowledge-related needs. In order to facilitate knowledge sharing, organizations not only need to consider the motivational factors or incentives, but, they also need to think about certain punitive measures, since the goal of implementing a successful and effective knowledge management system cannot be achieved only through incentives. That is why while talking about coercive measures participants suggested that the employee performance appraisal should include the factor of knowledge sharing and the promotions of the employees need to be tied with the knowledge sharing initiatives and offerings of the employees. The participants also emphasized promoting a knowledge sharing culture characterized by the values of mutual cooperation, open communication, collaborative work and healthy interpersonal relationship between organizational members. For the achievement of this goal, they especially stressed on promoting the concept of teamwork and full organizational support with all the required resources, tools and equipment necessary for knowledge sharing. They especially highlighted the role of organizational leadership which keeps central position in the facilitation of knowledge sharing within organizations.

\section{DISCUSSIONS}

This research was conducted to investigate the individual barriers to knowledge sharing in three health-care organizations. Based on the data analysis, unwillingness to share, absence of trust, deficiency of time, lack of appreciation and motivation and lack of cultural and language similarity were recognized as the most important individual blockages to KS. The existing literature suggests that attitude and intention toward sharing knowledge is a critical factor for knowledge sharing. In many situations, individuals show unwillingness to share knowledge due to a number of reasons including: lack of possession of valuable knowledge (Bures, 2003; Cabrera \& Cabrera, 2002), lack of intention to share knowledge with the view not to lose their power of knowledge by sharing (Santos et al., 2012). Unwillingness also includes lack of trust (Zhang \& Daves, 2006). Trust plays central role in the process of knowledge sharing to such an extent that without trust, it is almost impossible to talk of knowledge sharing (Wang \& Noe, 2010; Riege, 2005). In most of the cases, people seem to be unlikely to exchange knowledge if they do not possess a feeling of trust. Trust in knowledge sharing can have a number of dimensions. For example, trust in the sense that the sharer has accurate, authentic and credible knowledge to be shared. Trust in the sense that the receiver will would not misuse if the knowledge is shared with him or her. Sometimes people fail to get the time and sources to assess the authenticity of time and in that case also trust helps. Management neither can supervise nor force out individuals for knowledge sharing activities; however, a presence of trust between a company and its employees and within employees can have a positive and direct impact on the flow of communication and on the quantity and frequency of shared knowledge within individuals and units (De Long and Fahey, 2000; McAllister, 1995).

Time factor has been identified as a big hurdle to knowledge sharing in a number of research studies. For example, O'Dell and Grayson (1998) mentioned time deficiency as one of the most common barriers to KS, noting that managers despite knowing the advantages of sharing knowledge, often fail to enforce it owing to deficiency of time. Lack of time can also be one of the reason of hoarding knowledge. Hence, instead of sharing knowledge with others, individuals focus on the things that can be more advantageous (Michailova and Husted, 2003). Hew \& Hara (2007) have also found time 
constraint as a serious hurdle to knowledge sharing. Built on this, time factor can be treated a cost factor in the process of knowledge (Grant, 1996). Consequently, it seems imperative that work schedules should leave enough time and space to let people exchange ideas generate new knowledge and then also share with those individuals who need it. According to Gold et al (2001), lack of provision of places and time slots for employees where they can communicate, often result in knowledge sharing barriers. Many researchers have recommended that formal and informal structures augment employees' chances of sharing knowledge and gain new insights (e.g., Santos et al., 2012). However, the provision of informal spaces is rarely seen in organizations, due to the very widely spread strong perception among the managers that if organizational members are not doing something continuously, it means they are not working (Skyrme, 2000; Probst et al., 2000).

\section{Managerial Implications \& Conclusion}

This research paper unveils various aspects of knowledge sharing within professional working environment and highlights some critical factors that impede knowledge sharing within organizations especially in health care sector. The paper not only discusses the barriers to knowledge sharing, but also discusses the remedies in the light of the interviews of the same organizations. Hence, this paper offers a number of important implications for both researchers and practitioners.

Firstly, with respect to the factor of unwillingness to share, organizational management needs to change the perceptions of the organizational members toward knowledge sharing (Santos et al., 2012). Organizations need to inculcate the feeling among the employees that it is not knowledge, but the sharing of knowledge that is the basis of one's power position within organizations (Lilleoere \& Hansen, 2011; Bartol \& Srivastava; 2002; O'Dell \& Grayson, 1998). They need to tell the staff that if they don't share their knowledge, it will drain out, because the experience and common observation tells that knowledge is refreshed and refined by sharing and if not shared, it either obsoletes or wastes away (Dalkir, 2005). Moreover, organizational leadership need to change the thought of the staff members that they should not focus on individual achievements, rather they need to consider the overall organizational brilliance and success (Ribiere \& Sitar, 2003). For achieving this objective, management needs to strengthen the concepts of teamwork, common vision and mutuality of goals among the organizational members.

Based on the above discussion, it is therefore essential for the organizations to play active part in creating and maintaining an environment conducive for sharing of knowledge and cultivation of trust among the organizational members seems to be the most important element in this connection (Patrick, Rourke \& Phillips, 2000). In order to encourage sharing of knowledge, Ardichvili et al (2003) emphasize the cultivation of organizational trust to ensure trustworthiness within staff and safeguard the individuals from possible negative outcomes emanating from sharing knowledge due to certain administrative and procedural flaws. Organizational policies, regulations and sanctions are necessary to motivate organizational member to participate in knowledge exchange. If the security measures are placed to guard employees' self-interests they feel confident to donate knowledge, since they remain assured that the knowledge receiver will be reprimanded if he or she misuses the received information (Ford \& Chan, 2003).

The management also needs to efficiently address the issues of cultural differences and biases regarding knowledge sharing. The managers need to infuse a sense of mutual respect, cooperation and collaboration among the employees. The organizations need to inculcate a sense of organizational commitment and professionalism in order to mitigate the effects of cultural and ethnic differences. Moreover, sense of mutuality of goals fosters knowledge sharing among culturally diversified organizational members. This is also endorsed by McAllister (1995), who argues that in professional or organizational working environment which involves high level of interdependence, peer performance leaves a drastic impact on individuals' performance, and the evidence that peers perform 
role responsibilities reliably will enhance fellow workers' perception towards their colleagues' trustworthiness' (McAllister, 1995). Language differences and biases are also detrimental towards sharing of knowledge and the organizational leadership needs to ponder over this particular aspect also as Du Plessis (2003) emphasizes, that while designing knowledge management systems, firms need to take language differences into consideration if they want to receive the benefits of the same.

No one can deny the role of individual employee motivation for knowledge sharing as it is said "you can lead a horse to water, but you cannot make it drink". Effective knowledge sharing needs creation of a "grass root desire among employees to tap into their company's intellectual resources" (Hauschild et al., 2001). Until and unless the individuals are not motivated, no rules, no disciplinary actions, investment initiatives, technological and infrastructural developments can induce them to share the knowledge. Hence, it is extremely important to introduce and implement a rigorous package of financial and non-financial, direct and indirect incentives and rewards to motivate and encourage organizational members to share their knowledge, since incentive programs can spur and strengthen the positive attitude and environment required for successful knowledge sharing (Wong, 2005). And last but not the least, organizational leadership's role is the most crucial in the running discussion (Horak, 2001; Holsapple \& Joshi, 2000). Organizational managers need to exemplify the required knowledge sharing behaviors, since other employees follow their footsteps and behaviors. They should come forward as role models and set excellent and encouraging examples by showing their generosity and selfless willingness to exchange their knowledge with teammates and generate an ambience of cooperation and support among the organizational members (Wong, 2005).

\section{REFERENCES}

Adler, P. S., \& Kwon, S. W. (2002). Social capital: Prospects for a new concept. Academy of management review, 27(1), 17-40.

Alavi, M. \& Leidner, D.E. (2001). Review: Knowledge management and knowledge management systems: Conceptual foundations and research issues. MIS Quarterly, 25(1), 107-32.

Ardichvili, A., V. Page \& T. Wentling (2003). Motivation and Barriers to Participation in Virtual Knowledge-Sharing Communities of Practice. Journal of Knowledge Management 7(1), 6477.

Argote, L., Beckman, S., \& Epple, D. (1990). The Persistence and Transfer of Learning in Industrial Settings. Management Science, 36(2), 140-154.

Bartol, K. M., \& Srivastava, A. (2002). Encouraging knowledge sharing: The role of organizational reward systems. Journal of Leadership \& Organizational Studies, 9(1), 64-76.

Braun, V., \& Clarke, V. (2006). Using thematic analysis in psychology. Qualitative research in psychology, 3(2), 77-101.

Blaxter, L., Hughes, C. \& Tight, M. (1996). How to Research. Buckingham: Open University Press.

Bradfield, D. J., \& Gao, J. X. (2007). A methodology to facilitate knowledge sharing in the new product development process. International Journal of Production Research, 45(7), 14891504.

Bureš, V. (2003). Cultural barriers in knowledge sharing. E+ MEconomics and Management, 6, 5762.

Cabrera, A., \& Cabrera, E. F. (2002). Knowledge-sharing dilemmas. Organization studies, 23(5), $687-710$.

Casimir, G., Lee, K., \& Loon, M. (2012). Knowledge sharing: Influences of trust, commitment and cost. Journal of Knowledge Management, 16(5), 740-753.

Christensen, U., Schmidt, L. and Dyhr, L. (2008). The qualitative research interview, in Vallgaarda, S. and Kock, L. (Eds), Research Methods in Public Health, Gyldendal Akademisk, Copenhagen.

Currie, G., \& Kerrin, M. (2003). Human resource management and knowledge management: enhancing knowledge sharing in a pharmaceutical company. The International Journal of

Page $\mid 86$ 
Human Resource Management, 14(6), 1027-1045.

Dalkir. K. (2005). Knowledge Management in Theory and Practice. Elsevier Inc.

Davenport, T. H., De Long, D. W., \& Beers, M. C. (1998). Successful knowledge management projects. Sloan management review, 39(2), 43-57.

De Long, D.W. \& Fahey, L. (2000). Diagnosing cultural barriers to knowledge management. Academy of Management Executive, 14(4), 113-27.

Detmer, W. M., \& Shortliffe, E. H. (1997). Using the Internet to improve knowledge diffusion in medicine. Communications of the ACM, 40(8), 101-108.

Du Plessis, M. (2003). The role of knowledge management in eBusiness and customer relationship management. Doctoral thesis, University of Pretoria, Pretoria

$\mathrm{Du}$ Plessis, M. (2005). Drivers of knowledge management in the corporate environment. International journal of information management, 25(3), 193-202.

Eisenhardt, K. M. (1989). Building Theories from Case-Study Research. Academy of Management Review, 14(4), 532-550.

Gold, A.H., Malhotra, A. \& Segars, A.H. (2001). Knowledge management: an organizational capabilities perspective. Journal of Management Information Systems, 18(1), 185-214.

Grant, R. M. (1996). The knowledge based view of the firm: Implications for management practice. Long Range Planning, 30(3), 450-454.

Hauschild, S., Licht, T., \& Stein, W. (2001). Creating a knowledge culture. The McKinsey Quarterly, 74-74.

Hendriks, P. (1999). Why share knowledge? The influence of ICT on the motivation for knowledge sharing. Knowledge and Process Management, 6(2) 91-100.

Hew, K. F., \& Hara, N. (2007). Empirical study of motivators and barriers of teacher online knowledge sharing. Educational Technology Research and Development, 55(6), 573.

Horak, B. J. (2001). Dealing with human factors and managing change in knowledge management: a phased approach. Topics in health information management, 21(3), 8-17.

Husted, K. \& Michailova, S. (2002). Knowledge sharing in Russian companies with Western participation. Management International, 6(2), 17-28.

Ingram, P. \& Baum, J.A.C. (1997). Opportunity and constraint: organizations learning from the operating and competitive experience of industries. Strategic Management Journal, 18, special Summer issue, 75-98.

Jarvenpaa, S. L., \& Staples, D. S. (2001). Exploring perceptions of organizational ownership of information and expertise. Journal of Management Information Systems, 18(1), 151-183.

Kimble, C., Grenier, C., \& Goglio-Primard, K. (2010). Innovation and knowledge sharing across professional boundaries: Political interplay between boundary objects and brokers. International Journal of Information Management, 30(5), 437-444.

KPMG, (2003). Knowledge Management Research Report, http://www.kpmg.com.

Kukko, M. (2013). Knowledge sharing barriers in organic growth: A case study from a software company. The Journal of High Technology Management Research, 24(1), 18-29.

Kvale, S. (1996). Interviews: An introduction to Qualitative Research Interviewing. Sage Thousand Oaks. CA Google Scholar.

Levy, M., Hadar, I., Greenspan, S., \& Hadar, E. (2010). Uncovering cultural perceptions and barriers during knowledge audit. Journal of Knowledge Management, 14(1), 114-127.

Lilleoere, A. M., \& Holme Hansen, E. (2011). Knowledge-sharing enablers and barriers in pharmaceutical research and development. Journal of knowledge management, 15(1), 5370.

Lin, C., Tan, B., \& Chang, S. (2008). An exploratory model of knowledge flow barriers within healthcare organizations. Information \& Management, 45(5), 331-339.

Lindsey, K. (2003). Unmasking barriers to knowledge sharing using a communication framework. AMCIS 2003 Proceedings, 448.

Lugger, K. M., \& Kraus, H. (2001). Mastering the human barriers in knowledge management. Journal of Universal Computer Science, 7(6), 488-497. 
McAllister, D.J. (1995). Affect- and cognition-based trust as foundations for interpersonal cooperation in organizations. Academy of Management Journal, 38(1), 24-59.

McDermott, R. \& O'Dell, C. (2001). Overcoming Cultural Barriers to Sharing Knowledge. Journal of Knowledge Management, 5 (1), 76-85.

McNeish, J., \& Mann, I. J. S. (2010). Knowledge sharing and trust in organizations. IUP Journal of Knowledge Management, 8(1/2), 18-38.

Meyer, P. (2002). Improvisation power. Executive Excellence, 19(12), 17-18.

Michailova, S. \& Husted, K. (2003). Knowledge sharing in Russian companies with western participation. Management International, 6(2), 19-28.

Moeller, K. \& Svahn, S. (2004). Crossing East-West boundaries: knowledge sharing in intellectual business networks. Industrial Marketing Management, 33(3), 219-28.

Mooradian, T.A., Renzl, B. \& Matzler, K. (2006). Who Trusts? Personality, Trust and Knowledge Sharing. Management Learning, 37(4), 523-540.

Murray, P. (2002). Knowledge management as a sustained competitive advantage. Ivey Business Rowley, T., Behrens, D. \& Krackhardt, D. (2000). Redundant governance structures: an analysis of structural and relational embeddedness in the steel and semiconductor industries. Strategic Management Journal, 21,369-86.

Nahapiet, J. \& Ghoshal, S. (1998). Social capital, intellectual capital, and the organizational advantage. The Academy of Management Review, 23(2), 242-66.

O'dell, C., \& Grayson, C. J. (1998). If only we knew what we know: Identification and transfer of internal best practices. California management review, 40(3), 154-174.

Patrick, K., Rourke, G., \& Phillips, N. (2000). Issues of trust in knowledge management. Vine, 30(4), 44-51.

Patton, M. Q. (1990). Qualitative evaluation and research methods. SAGE Publications, inc.

Probst, G., Romhardt, K., \& Raub, S. (2000). Managing knowledge: Building blocks for success. J. Wiley.

Renzl, B. (2008). Trust in management and knowledge sharing: the mediating effects of fear and knowledge documentation. Omega, 36(2), 206-20.

Ribiere, V. M., \& Sitar, A. S. (2003). Critical role of leadership in nurturing a knowledge-supporting culture. Knowledge Management Research \& Practice, 1(1), 39-48.

Riege, A. (2005). Three-dozen knowledge-sharing barriers managers must consider. Journal of Knowledge Management, 9(3), 18-35.

Ring, P. S., \& Van de Ven, A. H. (1994). Developmental processes of cooperative inter-organizational relationships. Academy of management review, 19(1), 90-118.

Santos, V. R., Soares, A. L., \& Carvalho, J. Á. (2012). Knowledge sharing barriers in complex research and development projects: an exploratory study on the perceptions of project managers. Knowledge and Process Management, 19(1), 27-38.

Sharp, D. (2003). Knowledge management today: challenges and opportunities. Information systems management, 20(2), 32-37.

Siakas, K. V., Georgiadou, E., \& Balstrup, B. (2010). Cultural impacts on knowledge sharing: empirical data from EU project collaboration. Vine, 40(3,4), 376-389.

Skyere, D. (2000). Knowledge Management: Making Sense of an Oxymoron, http://www.skyrme.com/pubs/knwstrat.htm. Accessed 13 November 2001.

Stake, R.E. (2006). Multiple Case Study Analysis. The Guilford Press, London.

Szulanski, G. (1996). Exploring internal stickiness: Impediments to the transfer of best practice within the firm. Strategic Management Journal, 17, no. Winter Special Issue, 27-43.

Vajjhala, N. R. (2013). Key barriers to knowledge sharing in medium-sized enterprises in transition economies. International Journal of Business and Social Science, 4(14).

Wang, S., \& Noe, R. A. (2010). Knowledge sharing: A review and directions for future research. Human Resource Management Review (20) 115-131.

Wilmot, A. (2005). Designing sampling strategies for qualitative social research: with particular reference to the Office for National Statistics Qualitative Respondent Register. Survey

Page $\mid 88$ 
IBT Journal of Business Studies

methodology bulletin-office for national statistics- 56,53 .

Yeşil, S., \& Hirlak, B. (2013). An empirical investigation into the influence of knowledge sharing barriers on knowledge sharing and individual innovation behaviour. International Journal of Knowledge Management (IJKM), 9(2), 38-61.

Zawawi, A. A., Zakaria, Z., Kamarunzaman, N. Z., Noordin, N., Sawal, M. Z. H. M., Junos, N. M.,\& Najid, N. S. A. (2011). The study of barrier factors in knowledge sharing: A case study in public university. Management Science and Engineering, 5(1), 59-70.

Zhang, J., \& Dawes, S. S. (2006). Expectations and perceptions of benefits, barriers, and success in public sector knowledge networks. Public Performance \& Management Review, 29(4), 433466. 